\title{
Competencia Emprendedora: La Experiencia de iNNoVaNDiS
}

\author{
Entrepreneurial Competence: The Experience of iNNoVaNDiS
}

Competência empreendedora: a experiência de iNNoVaNDiS

Asunción Ibáñez-Romero* https://orcid.org/0000-0002-7238-8740

Departamento de Estrategia y Sistemas, Deusto Business School, University of Deusto

Jon Mikel Zabala-Iturriagagoitia** https://orcid.org/0000-0003-1975-2555

Departamento de Economía, Deusto Business School, University of Deusto

$\nabla$

Recibido: 27-02-18 Revisado: 09-06-18 Aceptado: 10-09-18 Publicado: 20-12-18

- Resumen. En este artículo se describe el perfil de la persona emprendedora desde una perspectiva académica, para su posterior contraste con la forma en la que dichas competencias son desarrolladas en el Título Propio de Especialización en Innovación y Emprendimiento (Programa iNNoVaNDiS) de la Universidad de Deusto en su Campus de San Sebastián (España). Este programa desarrolla y promueve el comportamiento emprendedor entre todos los estudiantes de dicho campus, trabajando en conocimientos, habilidades, actitudes, valores y emociones relacionadas con el mismo. En el artículo se comparten las bases y la filosofía del programa, y se contrasta con antiguas y antiguos estudiantes del mismo (48 estudiantes, 54\% hombres y 46\% mujeres) qué ha supuesto para ellas y ellos participar en iNNoVaNDiS. Las respuestas obtenidas de personas que actualmente se encuentran trabajando en diferentes países, sectores y puestos nos permite identificar cuáles de las competencias que se trabajan en el programa son las más valoradas por el mercado de trabajo.
Palabras clave:

Innovación;

Emprendimiento;

Educación

Superior;

Competencias;

Entrevista. 
Abstract. This article describes the profile of the entrepreneur from an academic perspective, for its subsequent comparison with the way in which these skills are developed in the Specialization in Innovation and Entrepreneurship Degree (iNNoVaNDiS Program) of the University of Deusto at its San Sebastian campus(Spain). This program develops and promotes entrepreneurial behavior among all students in campus, working on knowledge, skills, attitudes, values, and emotions related to it. The article shares the bases and philosophy of the program. It also contrasts the previous bases vis a vis the alumni of the said program (48 students: $54 \%$ men and $46 \%$ women) discussing what has meant for them to participate in iNNoVaNDiS. The answers obtained from these individuals who are currently working in different countries, sectors, and positions allow us to identify which of the competences that are worked in the program are most valued by the labor market.

- Resumo. Neste artigo descreve-se o perfil da pessoa empreendedora desde uma perspectivaacadêmica, paracontrastá-lacomaforma emqueassuascompetênciassão desenvolvidas no Título Próprio de Especialização em Inovação e Empreendimento (Programa iNNoVaNDiS) da Universidade de Deusto em seu Campus de San Sebastián (Espanha). Este programa desenvolve e promove o comportamento empreendedor entre todos os estudantes do campus, através do trabalho centrado em conhecimentos, habilidades, atitudes, valores e emoções relacionadas com tal comportamento. No artigo compartilham-se as bases e a filosofia do programa, e contrasta-se com estudantes antigas e antigos (48 estudantes, 54\% homens e $46 \%$ mulheres) sobre o que significou para elas e eles participar em iNNoVaNDiS. As respostas obtidas por parte de pessoas que atualmente trabalham em diferentes países, setores e postos permitiram identificar quais das competências que se trabalham no programa são as mais valorizadas no mercado de trabalho.
Keywords:

innovation, entrepreneurship, higher education, competences, interview

Palavras-chave: Inovação; Empreendimento; Educação Superior; Competências; Entrevista.

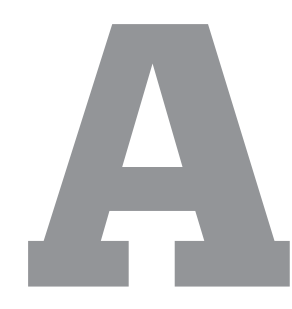

prender a conocer, a hacer, a vivirjuntos, a sery a emprender (añadido posteriormente por Federico Mayor Zaragoza1) son los rasgos del nuevo sistema educativo, según destaca Retegui (2001), citando el Informe de la Comisión Internacional sobre la Educación (informe Delors, 1996). La evolución que está teniendo el contexto al que las instituciones de educación tratan de dar respuesta está conllevando a que uno de los

1 El profesor Federico Mayor Zaragoza, entonces Director General de la Unesco, añadió este quinto aspecto durante su discurso en la Conferencia Regional sobre Políticas y Estrategias para la Transformación de la Educación Superior en América Latina (La Habana, noviembre de 1996). 
nuevos objetivos del sistema educativo sea el de promover un desarrollo integral de la persona y formar ciudadanos responsables, informados y comprometidos, que luchen por un futuro mejor para la sociedad (Unesco, 1998). El sentido de la iniciativa, entendido como una actitud ante la vida, y definido como la habilidad de la persona para transformar las ideas en actos, también es algo que destaca la Unión Europea (2006) en su Diario Oficial.

El comportamiento emprendedor es algo que se está demandando de forma creciente en el contexto actual, y, por tanto, el desarrollo de competencias emprendedoras entre las graduadas y los graduados universitarios es una función a considerar por las instituciones de educación superior, así como por parte tanto del sector empresarial como de otro tipo de empleadores (Gibb, Haskins \& Robertson, 2009).

Cada vez son más los centros educativos e instituciones de educación superior que apuestan por formar en este tipo de competencias, y el Título Propio de Especialización en Innovación y Emprendimiento (en adelante Programa iNNoVaNDiS) de la Universidad de Deusto en su Campus de San Sebastián es un ejemplo de ello. El programa iNNoVaNDiS comenzó su andadura en 2005, como resultado de la colaboración entre la Universidad de Deusto (Deusto Business School y Fundación Deusto), la Administración Pública (SPRI del Gobierno Vasco y Diputación Foral de Gipuzkoa) y la empresa privada (Ibermática y la Fundación Innovación Bankinter). iNNoVaNDiS consiste en un programa voluntario de tres años de duración, que es complementario para todos los estudiantes de dicho campus, sea cual fuere el grado o doble grado que estén cursando. Este programa entiende que ser una persona emprendedora radica en una manera de pensar, una forma de actuar y una identidad personal, y trabaja generando las condiciones adecuadas a través de diferentes contextos que saquen a las y los estudiantes de su zona de confort y afronten la incertidumbre y el cambio con un claro enfoque orientado a la acción. El objetivo último es que las y los estudiantes se sientan capaces de cambiar las cosas y experimenten el fracaso lo más rápido posible, y no que éstos terminen con la implementación de una idea empresarial.

En Ibáñez-Romero y Zabala-Iturriagagoitia (2016) se aclara que la filosofía sobre la que se sostiene el programa consiste en que la iniciativa empresarial y la innovación no son objetivos o disciplinas por "aprender" (ver Alda, 2010) sino actitudes a interioriza para entrenar comportamientos, y que sus efectos van más allá de iniciar un negocio. Por tanto, el objetivo que se persigue no es el de acabar con una start-up, que es la forma habitual en la que se entiende el emprendimiento tanto por las instituciones de educación superior como por las instituciones públicas, sino estimular un comportamiento emprendedor e innovador de manera ética en la vida cotidiana.

Tal y como recogen Ibáñez et al. (2014), “el emprendimiento, y más concretamente la figura de la persona emprendedora, son fenómenos estudiados desde múltiples disciplinas: teoría económica, erradicación de la pobreza, desarrollo económico, creación de empresas, 
psicología, etc. Su importancia radica en el papel de la persona emprendedora como generadora de riqueza social (creación de puestos de trabajo, integración, distribución, etc.) así como económica (reinversión de beneficios, desarrollo económico) y ecológica (apoyo a la sostenibilidad medioambiental)" (pp. 22). Estos autores citan a Schumpeter (1942) al explicar que la persona emprendedora se entiende como un agente de cambio que provoca innovaciones (cambios) que generan riqueza, enfatizando que dicho proceso innovador no tiene por qué limitarse a la introducción de nuevos productos, servicios y/o procesos (i.e. innovación tecnológica), sino que también puede adoptar la forma de innovaciones orientadas a tener un impacto social o medioambiental, a la apertura de nuevos mercados emergentes, e incluso al cambio organizacional en el seno de organizaciones ya existentes. Del mismo modo, y citando a Yunus (2006), remarcan el papel clave de la persona para el desarrollo social y económico, destacando la capacidad del ser humano de provocar cambios tanto para sí mismo como para su entorno cercano.

Estas personas generadoras de cambios tienen una visión crítica y afrontan la vida con un componente muy importante de iniciativa, superando sus miedos y tomando las riendas de su desarrollo personal y profesional. Son personas que si atendemos a la definición que ofrece Cubeiro (2008) se podría decir que tendrían talento. Este autor define el talento como la capacidad de poner en valor lo que uno sabe, quiere y puede hacer. El talento es entendido por Cubeiro como la suma de "capacidad" (aptitud - conocimientos y habilidades-y actitud -comportamientos-) y "compromiso" (convertir la energía potencial en energía cinética). La persona emprendedora sería, por tanto, un agente de cambio que promueve que las cosas sucedan, y lo hace retando al status quo (Schumpeter, 1942). De ahí que Kirby (2007) afirme que el sistema educativo debe crear personas que puedan innovar - personas que puedan ver oportunidades y asumir la responsabilidad de hacerlas realidad y, en el proceso, provocar cambio. Según la Real Academia Española (RAE), las personas emprendedoras "tienen la capacidad de descubrir y evaluar oportunidades, reunir los recursos necesarios para aprovecharlas, y obrar de forma adecuada para lograr el éxito", por lo que podemos decir que existen en todos los ámbitos (artes, deporte, empresa, política, etc.), no sólo en el empresarial.

El Programa iNNoVaNDiS se apoya en la definición de Timmons (2000), según la cual la persona emprendedora tiene la habilidad de crear y construir algo de prácticamente nada, lo que supone iniciar, hacer, conseguir y construir. Para ello, la persona emprendedora requiere de las competencias y habilidades que le permitan identificar oportunidades donde otros ven caos, contradicción y confusión. Otras definiciones que apoyan esta visión se muestran en la Tabla 1. 
Tabla 1

Definiciones de emprender y/o persona y/o proceso emprendedor adoptadas por el programa iNNoVaNDiS

\begin{tabular}{|c|c|}
\hline Autor & Definición \\
\hline $\begin{array}{l}\text { Programa } \\
\text { iNNoVaNDis }\end{array}$ & $\begin{array}{l}\text { Persona emprendedora como generadora de cambios, tanto a nivel } \\
\text { personal como de su entorno, y que desembocan en la generación de } \\
\text { riqueza social, económica y ecológica. }\end{array}$ \\
\hline $\begin{array}{l}\text { Timmons } \\
(2000)\end{array}$ & $\begin{array}{l}\text { Habilidad de crear y construir de la nada, identificando oportunidades } \\
\text { de manera constante. }\end{array}$ \\
\hline $\begin{array}{l}\text { Kwiatkowki } \\
\text { (2004) }\end{array}$ & $\begin{array}{l}\text { Capacidad de percibir oportunidades y sacar provecho de ellas } \\
\text { explotando los recursos necesarios. }\end{array}$ \\
\hline $\begin{array}{c}\text { Kuratko } \\
(2005)\end{array}$ & $\begin{array}{l}\text { Proceso dinámico de visión, cambio y creación que necesita de la } \\
\text { aplicación de energía y pasión en la creación de nuevas ideas y } \\
\text { soluciones creativas. }\end{array}$ \\
\hline $\begin{array}{l}\text { Bolton y Thompson } \\
\qquad(2004)\end{array}$ & $\begin{array}{l}\text { Personas que alteran ciertas condiciones con la idea de crear valor } \\
\text { en torno a oportunidades percibidas, bien dentro de una empresa } \\
\text { existente o como una nueva aventura empresarial. El valor puede ser } \\
\text { de carácter financiero, social, o capital estético. }\end{array}$ \\
\hline $\begin{array}{l}\text { Collins, Smith y Hannon } \\
\text { (2006) }\end{array}$ & $\begin{array}{l}\text { Habilidad de gestionar la incertidumbre en el entorno y enfrentarse } \\
\text { al caos y la ambigüedad del cambio. }\end{array}$ \\
\hline
\end{tabular}

Fuente: Ibáñez et al. (2014).

Con base en estas definiciones, iNNoVaNDiS propone que el primer paso para motivar a las y los estudiantes de cualquier disciplina a ser emprendedoras/es, es hacer constar desde el proceso educativo que el ser emprendedor no implica necesariamente el tener que crear una empresa, pero sí llevar a cabo un proyecto de cualquier índole (Ibáñez et al, 2014: 23). Estos autores proponen un cambio en el paradigma de la educación tradicional en emprendimiento, que se ciñe a la creación de empresa, y abogan por formar personas que sean innovadoras, asuman la responsabilidad de su propio destino y que tengan una actitud positiva hacia la acción más allá de un contexto meramente empresarial. 


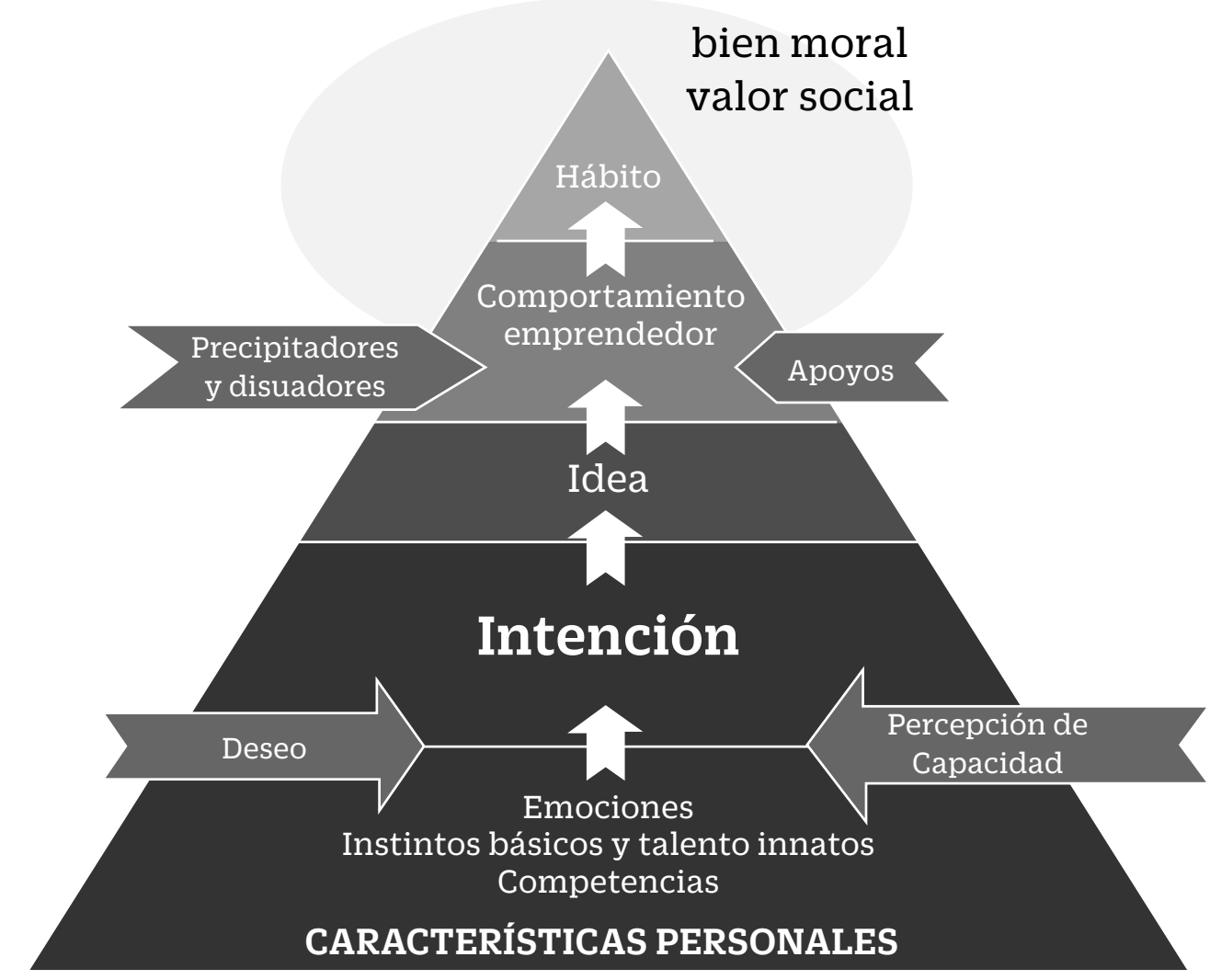

Figura 1. Pirámide del comportamiento emprendedor y esquema de actuación. Fuente: Ibáñez et al. (2014).

Ibáñez et al. (2014) afirman que el hábito emprendedor es un activo al que se llega si previamente se dan otros condicionantes, aproximación que confluye con Getley² (1979) y Florin et al. (2007), para quienes el comportamiento emprendedor viene precedido de una intención ${ }^{3}$, que a su vez parte de unos drivers ${ }^{4}$ del emprendimiento (ver Figura 1).

Según Ibáñez (2002), toda persona, antes de decidirse por abordar su propio proyecto, pasa por un periodo de maduración que viene en parte determinado por sus propias características personales, que es a su vez modulado por el entorno, tal y como están demostrando las nuevas aproximaciones que, desde la biología molecular, están evidenciando el carácter epigenético de la evolución tanto humana como organizacional (ver Gómez-Uranga et al, 2016).En este primer eslabón subyacen tres conceptos diferentes: los instintos básicos y talentos innatos, las emociones y las competencias, las cuales incluyen conocimientos, normas, técnicas, procedimientos, habilidades, destrezas, actitudes y valores ${ }^{5}$.

2 "[Mi motivación] es generar ideas de cómo podemos incrementar la valiosa combinación de cualidades personales, competencias y actitudes, a los que he llamado el driver emprendedor. He usado este término porque no puedo pensar en otro mejor que describa el impulso que algunas personas sienten para crear cosas, la determinación que tienen de lograr un progreso real, y la tenacidad que muestran para cambiar las cosas a pesar de tener una oposición masiva" (Getley, 1979: 19).

3 Ibáñez et al. (2014) aclaran que la intención no es sólo una expectativa, sino un compromiso proactivo para llevarla a cabo.

4 "El driver emprendedor es la percepción individual de la deseabilidad y viabilidad de perseguir de manera proactiva oportunidades y responder de manera creativa a los retos, tareas, necesidades y obstáculos de manera innovadora. Los individuos con altos niveles de driver emprendedor son generalmente grandes triunfadores, poseen un alto nivel de auto eficacia, cuestionan el status quo y tienen preferencia por soluciones innovadoras" (Florin et al, 2007: 26).

5 Ver Villa y Poblete (2007). 
Comenzando por los talentos innatos e instintos básicos, existe una parte de la persona sobre la que no se puede actuar porque, según Krauss (2008), citando a Freire (2004), todos tenemos unos talentos inmodificables que vendrían determinados por nuestras bases genotípica y fenotípica. Las emociones son importantes porque no podemos olvidar el vínculo emocional que existe entre las personas emprendedoras y sus proyectos (Tracey y Phillips, 2007). De hecho, según Southon y West (2005), para las personas emprendedoras el trabajo se convierte en algo que les permite "hacer lo que les gusta", incluso más que "hacer simplemente lo que quieren". Según Damasio (2005), las emociones y los sentimientos influyen en la toma de decisiones, tendiendo a reproducir comportamientos que dan placer y a omitir aquellos que producen displacer o dolor. Por esta razón, Goss (2008) propone una interacción social entre la parte cognitiva y la de las emociones que motive al emprendedor a pasar a la acción. Por todos es sabido que durante el proceso emprendedor una persona se encuentra con algunas de las emociones básicas como el disgusto, disfrute, miedo, amor, tristeza, sorpresa, vergüenza y repulsión que debe ser capaz de percibir, entender, controlar y modificar. Por tanto, el desarrollo de comportamientos emprendedores debe empezar a tomar en cuenta las emociones, los valores y los intereses de toda persona (Gibb, 2002). En este sentido, Ibáñez et al. (2014), de acuerdo con autores como Lebret (2007), Obermair (2008) y Cardon et al. (2005), destacan la importancia del entusiasmo y la pasión, abogando por un proceso de aprendizaje en el que no sólo exista un desarrollo cognitivo sino también afectivo (gustos y disgustos, sentimientos, emociones y estados de ánimo) y comportamental (motivación, compromiso, impulso y esfuerzo).

Por último, en lo que se refiere a las competencias, si tomamos la definición de Villa y Poblete (2007:24) una competencia puede ser entendida como "el buen desempeño en contextos diversos y auténticos basado en la integración y activación de conocimientos, normas, técnicas, procedimientos, habilidades y destrezas, actitudes $^{6}$ y valores ${ }^{7 "}$. Este conjunto de instintos básicos y talentos innatos, competencias y emociones compondrán el perfil de la persona emprendedora, sobre la que afectarían dos drivers principales del proceso emprendedor: el deseo personal y social percibido, y la viabilidad percibida o percepción de la propia capacidad para emprender. Estos drivers motivarán la intención de la persona de actuar de manera emprendedora. Es decir, la persona debe percibir que ser emprendedora está bien visto en el entorno, debe percibirse a sí misma como tal, y además, debe percibir que es viable que ella lo sea (Azjen, 1991; Shapero y Sokol, 1982; Getley, 1979; Florin et al, 2007). Sobre la importancia

\footnotetext{
6 Según Morales (2000: 24) la actitud se refiere a una predisposición aprendida, no innata, y estable a reaccionar de una manera valorativa favorable o desfavorable, ante un objeto (individuos, grupos, ideas, situaciones, etc.). Por su parte, Nunnally (1978: 590) las describe como sentimientos hacia objetos y estarían referidas hacia algo. La estructura de las actitudes suele ser concebida con tres componentes: el cognitivo (información, creencias), el afectivo (gusto-disgusto, valoración) y el conativo (tendencia a la acción). La actitud es menos estable que los rasgos de personalidad, cambia a través del tiempo y se modifica con la interacción del entorno (Robinson, 1987).

7 Según Elexpuru y Yaniz (2001: 2), siguiendo el modelo de Hall (1995), los valores se entienden como ideales que dan significado a la vida de cada persona, que guían, orientan y motivan sus decisiones y acciones. De acuerdo con el modo en que cada uno establece sus prioridades de valor surgen combinaciones únicas que reflejan la forma de ver el mundo y determinan sus actitudes.
} 
de estas dimensiones, la literatura evidencia cómo la viabilidad y credibilidad percibidas, así como la propensión a actuar, explican cerca del cincuenta por ciento de la varianza respecto al emprendimiento (Krueger y Brazeal, 1994, en Urban, 2006).

Es necesario por tanto que la persona desarrolle el deseo de convertirse en emprendedora para poder con posterioridad llegar a serlo, ejerciendo como tal, y creando las bases para que otras puedan seguir recorriendo dicha senda. Y, según hemos visto al citar a Damasio (2005), tenderemos a comportarnos de manera emprendedora si este comportamiento lo experimentamos como placentero. Este "deseo", uno de los dos drivers de Florin et al. (2007), sería la "verdadera motivación” que, según Trías de Bes (2007), impulsa a tener voluntad y luchar, dos aspectos fundamentales en todo proceso emprendedor.

El otro driveres la "percepción de la propia capacidad" para ser una persona emprendedora. Para ello, debemos contar con las herramientas ${ }^{8}$ necesarias y la suficiente autoestima como para percibirnos capaces de afrontar todo el proceso. Ibáñez et al. (2014) explican que la percepción de la propia capacidad y el deseo de comportase como tal, impulsan a la persona emprendedora a desarrollar una primera intención de comportamiento emprendedor. Una vez llegados a este punto, la persona está preparada y alerta ante las oportunidades que puedan surgir. Naturalmente, existen eventos precipitadores y disuasores que empujarán o retendrán a la misma en la toma de decisiones y en la búsqueda de apoyos externos como soportes financieros, asesoría legal, un entorno favorable de estabilidad socio-económico-política o la disponibilidad de recursos e infraestructuras, por ejemplo. Estos autores aclaran que llegado este momento, para que se trate de un proceso sostenible en el tiempo y no de un suceso puntual, no debe ser un comportamiento puntual sino interiorizarse y transformarse en un hábito; en una forma de vida.

Por último, la culminación del proceso se da cuando hacemos lo que sabemos hacer bien en pos del bien común (inteligencia moral). O lo que es lo mismo, el "make meaning" que Kawasaki (2004) advierte que debe cumplir cualquier proceso emprendedor: hacer algo con sentido, es decir, "buscar el valor social y el bien moral, como medio para obtener la sostenibilidad económica y social del nuevo proyecto y su entorno" (Ibáñez et al, 2014: 34).

En este sentido, y de acuerdo con Alda (2010) consideramos que es preciso discernir entre: sensibilizar (tomar conciencia y comprender), posicionar las opciones emprendedoras como alternativas de carrera (motivación), promocionar las cualidades personales relacionadas con el emprendimiento, formar en competencias específicas para emprender, y generar valor. Alda (2010) asigna cada uno de estos objetivos a una etapa del currículo educativo, confluyendo todos ellos en la educación superior. En lo que respecta al programa iNNoVaNDis, todos estos elementos quedan identificados e incluidos en el mismo, ya que nace y se retroalimenta de

8 La percepción de la propia capacidad puede entenderse a su vez como el conjunto de conocimientos, normas, técnicas, procedimientos, habilidades y destrezas, actitudes y valores, que vendrían incluidos en los cinco dominios de la inteligencia emocional de Goleman et al. (2002). 
la experimentación, de la prueba, de la búsqueda de vías para lograr el interés de las y los estudiantes por otras formas de hacer (Ibáñez et al, 2014). Pero, como nos recuerdan IbáñezRomero y Zabala-Iturriagagoitia (2016), esta experimentación también tiene un proceso de observación y testeo a través de la línea de investigación en emprendimiento dentro de la UD, cuyos resultados enriquecen a ambas actividades.

El programa cuenta con un enfoque práctico, de reflexión en acción, de aprender haciendo, dado que estamos hablando de un comportamiento. El programa iNNoVaNDiS es voluntario, adicional al grado o doble grado cursado y dura tres años en los que las y los estudiantes toman parte activa en diferentes talleres y actividades (ver Figura 2).

\begin{tabular}{|c|c|c|c|}
\hline $1^{\circ}$ TITULO & $2^{\circ}$ TITULO & \multicolumn{2}{|c|}{$3^{\circ}$ TITULO } \\
\hline $2^{\circ}$ Grados $/ / 3^{\circ}$ Dobles & $3^{\circ}$ Grados $/ / 4^{\circ}$ Dobles & \multicolumn{2}{|c|}{$4^{\circ}$ Grados $/ / 5^{\circ}$ Dobles } \\
\hline $2^{\circ}$ Semestre & Año completo & Verano de $2^{\circ}$ y $3^{\circ}$ & $2^{\circ}$ Semestre \\
\hline 9 ECTS & 9 ECTS & \multicolumn{2}{|c|}{12 ECTS } \\
\hline $\begin{array}{l}\text { Taller de Etornos en Red } \\
\text { - DO I. T.- } \\
\text { (1ECS) }\end{array}$ & \multirow{2}{*}{$\begin{array}{c}\text { Curso de Innovación } \\
\text { - EL NUEVO LENGUAJE DE } \\
\text { LA INNOVACIÓN - } \\
\text { (3CTS) }\end{array}$} & \multirow{6}{*}{$\begin{array}{l}\text { Prácticas en } \\
\text { empresas } \\
\text {-MISIÓN } \\
\text { iMPLOSIÓN- } \\
\text { (6ECTS) }\end{array}$} & \multirow{6}{*}{$\begin{array}{l}\text { Desarrollo de } \\
\text { Proyecto } \\
\text { - GO FOR IT! - } \\
\text { (6 ECTS) }\end{array}$} \\
\hline $\begin{array}{l}\text { Taller en Busca de mi } \\
\text { emprendedor }\end{array}$ & & & \\
\hline $\begin{array}{l}\text { - WANTED - } \\
\text { (3ECS) }\end{array}$ & \multirow{2}{*}{$\begin{array}{c}\text { Curso de generación } \\
\text { de ideas de proyecto } \\
\text {-INNOVACIÓN } 360 \text { - } \\
\text { (3CTS) }\end{array}$} & & \\
\hline $\begin{array}{c}\text { Taller de Orientación } \\
\text { Personal }\end{array}$ & & & \\
\hline (2ECS) & \multirow{2}{*}{$\begin{array}{l}\text { Desarrollo de Proyecto I } \\
\text { - YES, U CAN! - } \\
\text { (3ECTS) }\end{array}$} & & \\
\hline $\begin{array}{c}\text { Taller de Creatividad } \\
\text { - SHAKE AWAY- } \\
\text { (1ECS) }\end{array}$ & & & \\
\hline
\end{tabular}

Figura 2. Estructura del programa iNNoVaNDiS. Fuente: Elaboración propia.

A modo de síntesis, los principios básicos que identifican Ibáñez-Romero y ZabalaIturriagagoitia (2016) en el programa iNNoVaNDiS pueden sintetizarse en los siguientes:

La persona

La emoción y la diversión

La acción y el comportamiento 
Los valores

- La multidisciplinariedad y transversalidad

El mejor ejemplo de cómo trabaja el programa la importancia de la persona es el taller de orientación personal y la figura del coach que acompaña a las y los estudiantes durante los tres años que dura el programa, para ayudarles a mirar hacia dentro, conocerse a sí mismos, y ganar confianza, dado que esto es fundamental en los entornos de incertidumbre y riesgo en los que probablemente tengan que moverse en un futuro. Hay muchos autores como Lankard, (1995), Brown (1999), Siemon y Otter (2007), Van Burg et al. (2008), Römer-Paakkanen y Pekkala (2008) o Garand (2009) que destacan la importancia del coaching en procesos emprendedores. Aquí es donde trabajan los temas actitudinales como el propósito, el autoconocimiento, la asertividad o la comunicación positiva que hemos destacado anteriormente. Se trata de que hagan un autodiagnóstico que les permita analizar sus capacidades y actitudes para identificar sus debilidades y potenciar sus fortalezas.

En cuanto a la emoción, característica intrínseca de cualquier persona, ya hemos subrayado el porqué de su importancia y el programa da su espacio a las emociones, no sólo trabajando sobre la inteligencia emocional de sus participantes, sino haciendo del mismo una experiencia emocionante y divertida, para lo que se vale de símbolos, rituales, discurso, lenguaje, recuerdos en fotografías y vídeos, etc.... "iNNoVaNDiS cree en el aprendizaje y trabajo riguroso disfrutando” (Ibáñez-Romero y Zabala-Iturriagagoitia, 2016:202). Y estolo hacen respaldados por otros autores que también abogan por una formación en emprendimiento divertida (Tracey y Phillips, 2007; Southon y West, 2005; Gibb, 2002; Lebret, 2007; Obermair, 2008; Cardon et al, 2005), lo cual no está en conflicto con el rigor, que también se trabaja en varios de los talleres de los que se compone el programa. Sin embargo, no sólo las emociones placenteras tienen cabida en el programa, sino también otras negativas como el temor, el miedo, la inseguridad o la vergüenza, a las que también tendrán que hacer frente en cualquier proceso, tanto emprendedor e inestable, por la incertidumbre asociada a estos procesos de cambio, como en procesos orientados a mantener el status quo. Por ello, iNNoVaNDiS genera espacios que saquen a las y los participantes de su zona de confort, ofreciéndoles herramientas y entrenamiento en la percepción, uso, comprensión y regulación de esas emociones (inteligencia emocional).

Como ya hemos explicado anteriormente, la acción es un elemento consustancial a iNNoVaNDiS, ya que si buscamos que los iNNoVaNDeRS (personas que han cursado el programa iNNoVaNDiS) generen cambios en sus entornos reales, debemos con anterioridad entrenarlos para alcanzar tal fin. En el programa, las y los estudiantes trabajan sobre retos reales en colaboración con organizaciones locales que conocen en contextos que pretendes sacarles de su zona de confort para que experimenten la incertidumbre y el cambio y se enfrenten al fracaso lo antes posible para poder aprender de él. Se trata por tanto de generar comportamientos emprendedores e innovadores en el día a día, más allá del lanzamiento del mayor número de 
start-ups posible. Las actitudes como la perseverancia, resiliencia o el trabajo en equipo tienen aquí un espacio real para su entrenamiento.

En la culminación del proceso emprendedor, ya hemos hecho referencia a la importancia de los valores éticos, sociales y medioambientales. El programa pretende que las y los estudiantes se hagan responsables de sus propias acciones y den prioridad a valores de justicia social. Se espera de ellas y ellos que "tengan un impacto positivo tanto en las organizaciones a las que eventualmente se dediquen, como en la sociedad en general" (Ibáñez-Romero y ZabalaIturriagagoitia, 2016: 202). Esta filosofía es la que les lleva a trabajar los temas actitudinales como la humildad, armonía o empatía. En la Tabla 2 podemos ver los valores que deberían trabajarse en la educación de actitudes emprendedoras según Morris y Schindehutte (2005), siguiendo la escala de Hall y Brian (1995).

\section{Tabla 2}

Valores que deberían trabajarse en la educación de actitudes emprendedoras

Superación personal: implica el desarrollo de una actitud proactiva, locus of control interno, auto-motivación de logro, etc. (vinculada con las actitudes emprendedoras).

Pertenencia a la comunidad (en un sentido amplio): implica el desarrollo de la empatía y la inteligencia social (integración y aportación a la sociedad, y la habilidad de la inteligencia emocional).

Sentimiento de justicia social: es la búsqueda del bien moral con mis acciones (vinculada al hábito emprendedor del proceso emprendedor).

Fuente: Ibáñez-Romero y Zabala-Iturriagagoitia (2016), a partir de Morris y Schindehutte (2005).

Ibáñez-Romero y Zabala-Iturriagagoitia (2016) explican que la filosofía sobre la que se fundamenta el programa es que ni el emprendimiento ni la innovación son disciplinas per se y que sus efectos van más allá de crear una empresa. Por ello, el programa se ofrece a todo el estudiantado de la UD en su campus de San Sebastián, sea cual fuere la disciplina en la que se estén formando. Para dar respuesta a tal multidisciplinariedad entre el alumnado, el programa también cuenta con un equipo formado por personas que provienen de disciplinas a menudo antagónicas, y que cuentan con perfiles muy diferentes, pero que son integradas de manera sistémica en elmismo (p.e.consultores, investigadores, académicos, coaches, artistas, ingenieros, emprendedores, actores, etc.). Esta mezcla de perfiles entre el estudiantado y el profesorado es una de las grandes riquezas del programa. Esta forma de entender la formación emprendedora se corresponde con el cuarto modelo de integración de los programas de emprendimiento en educación que proponen Heinonen y Hytti (2008), Frank (2007), la Comisión Europea (2008) o Lloyd-Reason et al. (2009) entre otros. 
En Ibáñez-Romero y Zabala-Iturriagagoitia, 2016 (pp. 205) se listan las características que, basándose en los trabajos de Alcaraz (2011), Krauss (2008) e Ibáñez (2002) sobre el perfil emprendedor, definen a la persona emprendedora para el programa en iNNoVaNDiS y que mostramos en la Tabla 3.

\section{Tabla 3}

Características del perfil emprendedor que trabaja el programa iNNoVaNDiS

Debe ser perseverante, comprometida, con determinación y energía, para poder trabajar duro y afrontar los muchos sacrificios a los que se enfrentará.

Debe tener iniciativa, flexibilidad, tolerancia al cambio, asunción de riesgos moderados y no temer al fracaso, para poder afrontar situaciones de incertidumbre, crecientes en entornos de alta velocidad como los actuales (Eisenhardt, 1989).

Debe ser una persona innovadora y con visión de futuro, orientación al mercado y al crecimiento para poder identificar oportunidades.

Debe tener una elevada motivación de logro y optimismo que le empujen y le ayuden a forjar el deseo de ser emprendedor.

Debe tener altos niveles de autoestima y un control percibido interno que le permitan afrontar los posibles fracasos y lanzarse a nuevos retos.

Debe tener una disposición proactiva, iniciativa y una gran dosis de compromiso, perseverancia y voluntad por lanzar su proyecto (Baum y Locke, 2004).

También deben considerarse los valores personales del individuo como la honestidad, la sensación de deber, la responsabilidad y el comportamiento ético (Saboia y Martin, 2006; Quintero, 2007).

Fuente: Ibáñez-Romero y Zabala-Iturriagagoitia (2016: 205).

Con este estudio pretendemos contrastar con antiguas y antiguos estudiantes del programa iNNoVaNDis lo que ha supuesto para ellas y ellos participar en él. Nuestra hipótesis es que iNNoVaNDiS es un programa que está orientado a trabajar las competencias requeridas por las personas emprendedoras e innovadoras desde la acción. Para poder contrastar dicha hipótesis, el artículo trata de responder a la siguiente pregunta de investigación: ¿Cuáles son las competencias más valoradas por los iNNoVaNDeRs? Con este estudio pretendemos por lo tanto evaluar si el programa está teniendo el impacto que el mismo aspira a lograr a medio plazo, una vez que los iNNoVaNDeRs ya se encuentran en el mercado laboral, y son por lo tanto capaces de valorar las competencias que se trabajaron en el programa durante su etapa universitaria. 


\section{MÉTODO}

\section{Participantes}

Aproximadamente, la cantidad de estudiantes que son aceptadas y aceptados anualmente en cada generación o cohorte del programa ronda las 20 personas. En este curso académico 20172018 el programa va por su 14 edición y son 292 personas las que han conseguido culminar iNNoVaNDiS. De dicha población, para este estudio contactamos con 48 iNNoVaNDerS, por lo que contamos con una muestra que representa el 16,43\% del total de la población. La tabla 4 ofrece una estadística descriptiva sobre las 48 personas entrevistadas, incluyendo la distribución de la muestra en función de la generación a la que pertenecen, el número de años que pasan desde que acabaron el programa hasta que fueron entrevistados, el año en el que fueron entrevistados, así como la distribución en función del género.

Tabla 4

Estadística descriptiva sobre la muestra del estudio

\begin{tabular}{|c|c|c|c|c|c|c|c|c|c|c|c|c|c|c|c|c|c|}
\hline \multicolumn{3}{|c|}{ Generación } & \multicolumn{3}{|c|}{$\begin{array}{l}\text { Número de años que } \\
\text { pasan desde que } \\
\text { acaban el programa } \\
\text { hasta que hacen } \\
\text { entrevista }\end{array}$} & \multicolumn{3}{|c|}{ Año Entrevista } & \multicolumn{3}{|c|}{ Género } & \multicolumn{3}{|c|}{ Tipo de trabajo } & \multicolumn{3}{|c|}{ Lugar trabajo } \\
\hline & $\#$ & $\%$ & & $\#$ & $\%$ & & \# & $\%$ & & $\#$ & $\%$ & & $\#$ & $\%$ & & \# & $\%$ \\
\hline $1 G$ & 5 & $10 \%$ & 1 & 6 & $13 \%$ & 2012 & 4 & $8 \%$ & Hombre & 26 & $54 \%$ & $\begin{array}{l}\text { Emprendiemiento cuenta } \\
\text { ajena }\end{array}$ & 16 & $33 \%$ & Internacional & 14 & $29 \%$ \\
\hline $2 \mathrm{G}$ & 5 & $10 \%$ & 2 & 6 & $13 \%$ & 2013 & 11 & $23 \%$ & Mujer & 22 & $46 \%$ & $\begin{array}{l}\text { Emprendimiento cuenta } \\
\text { propia }\end{array}$ & 8 & $17 \%$ & Local & 25 & $52 \%$ \\
\hline $3 G$ & 3 & $6 \%$ & 3 & 10 & $21 \%$ & 2014 & 8 & $17 \%$ & & & & En búsqueda & 1 & $2 \%$ & Nacional & 9 & $19 \%$ \\
\hline $4 G$ & 12 & $25 \%$ & 4 & 12 & $25 \%$ & 2015 & 8 & $17 \%$ & & & & Familiar propia & 1 & $2 \%$ & & & \\
\hline $5 G$ & 6 & $13 \%$ & 5 & 5 & $10 \%$ & 2016 & 10 & $21 \%$ & & & & Gobierno & 1 & $2 \%$ & & & \\
\hline 6G & 8 & $17 \%$ & 6 & 3 & $6 \%$ & 2017 & 7 & $15 \%$ & & & & Multinacional & 12 & $25 \%$ & & & \\
\hline $7 \mathrm{G}$ & 4 & $8 \%$ & 7 & 1 & $2 \%$ & & & & & & & Pyme & 8 & $17 \%$ & & & \\
\hline $8 \mathrm{G}$ & 4 & $8 \%$ & 8 & 3 & $6 \%$ & & & & & & & Voluntariado & 1 & $2 \%$ & & & \\
\hline \multirow[t]{2}{*}{$9 \mathrm{G}$} & 1 & $2 \%$ & 9 & 2 & $4 \%$ & & & & & & & & & & & & \\
\hline & 48 & $1 \%$ & & 48 & $1 \%$ & & 48 & 1 & & 48 & 1 & & 48 & $1 \%$ & & 48 & 1 \\
\hline
\end{tabular}

Fuente: Elaboración propia.

La tabla anterior agrupa a su vez a las personas que constituyen la muestra en función del tipo de trabajo en el que desarrollaban su labor profesional en el momento en el que fueron entrevistadas. Para ello, se consideran las siguientes posibles categorías de trabajos: emprendedor por cuenta ajena, emprendedor por cuenta propia, en búsqueda de empleo, empresa familiar propia, gobierno o administración pública, empresa multinacional, pequeña y mediana empresa (pyme), o voluntariado. De igual modo, también se caracteriza la ubicación de dicho trabajo, en función de si dicha actividad se está desarrollando en el entorno local guipuzcoano, en el entorno nacional o de manera internacional. 


\section{Instrumentos de recolección de datos}

Los diálogos con antiguas y antiguos estudiantes se han producido en distintos momentos temporales; es decir, la recopilación de la información se ha ido produciendo a lo largo de los últimos años, y no en un rango temporal puntual. Todos los datos recopilados se encuentran publicados en el blog del programa, a partir del cual se comparte con la sociedad las actividades en las que se está trabajando en cada momento9. En dichos diálogos se les formulaban las preguntas que enumeramos a continuación:

- Recorrido profesional: ¿Qué ha sido de ti tras salir de iNNoVaNDiS?

- Motivación: ¿Qué es lo que más te apasiona de lo que haces?

- Próximos pasos: ¿Qué planes tienes de futuro?

- Pensamiento reflexivo sobre impacto del programa: ¿Qué has aprovechado de iNNoVaNDiS en tu desarrollo profesional?

A través de la última pregunta buscamos conocer si los años de experiencia en el mundo laboral permiten a las y los iNNoVaNDerRS identificar aquellas competencias de las que se les dotó en el programa, a pesar de que cuando lo cursaban, pudieran no ser conscientes ni de su utilidad ni de la ventaja competitiva que ello les iba a proporcionar en un mundo cada vez más rápido y cambiante.

\section{Procedimiento}

Para complementar la tabla 4, y utilizando las herramientas de minería de textos (i.e. textmining) disponibles, se ha realizado un análisis sintáctico de las entrevistas realizadas, en las cuales se destacan las principales ideas recogidas en las mismas. Para ello, se etiquetó cada respuesta con los conceptos relacionados con las 19 ideas clave que se habían extraído de todos esos comentarios y que listamos a continuación junto con las palabras con las que se resumió cada idea):

1. Acción, práctica, emprender, experiencia, proactividad, iniciativa (hacer que las cosas sucedan)

2. Actitud positiva (actitud positiva)

3. Afrontar retos y complicaciones, luchar, incomodidad, salir zona confort (afrontar retos)

4. Apertura de mente, curiosidad, inquietud, observador (curiosidad)

5. Conocerte mejor, Consciente (consciencia)

6. Incertidumbre, nuevo, diferente, aventura (afrontar incertidumbre)

7. Inconformismo y no rendirte, no existe el fracaso (inconformismo)

8. Innovación y creatividad, out of the box (innovación)

9. Motivación, ilusión y ganas (motivación) 
10. Networking, contacto, conversación (networking)

11. Descubrir, Oportunidad (aprovechar oportunidad)

12. Pasión, ilusión, satisfacción y diversión (pasión)

13. Pensamiento crítico, cuestionarte las cosas y reflexión (cuestionar status quo)

14. Tomar riendas de propia vida, creer en ti mismo y ser tú mismo (protagonista)

15. Trabajo en equipo, ser parte de un equipo, participar, familia, amigos (equipo)

16. Trabajo, esfuerzo, perseverancia, rigor

17. Valor, afrontar miedos, inseguridades, prejuicios y vergüenzas (afrontar miedos)

18. Valorar más las cosas, agradecimiento, devolver a la sociedad, aportar, cambiar el mundo, construcción de mundo mejor (conciencia social)

19. Volar, imaginación, sueño, inspiración (inspiración)

Por lo tanto, cada una de las 48 personas encuestadas podía hacer referencia en su respuesta a más de una idea clave y, de este modo, trabajamos con 222 declaraciones.

\section{Resultados}

Las figuras 3 y 4 incluidas a continuación muestran cómo muchos de los fundamentos que se pretenden trabajar en el programa iNNoVaNDiS, son efectivamente valorados por las y los iNNoVaNDeRs, como pueden ser la orientación hacia la acción, la capacidad de creer en uno mismo, el cuestionamiento del status quo, la conciencia social, la motivación, o la capacidad para afrontar miedos y la incertidumbre subyacente a cualquier proceso innovador.

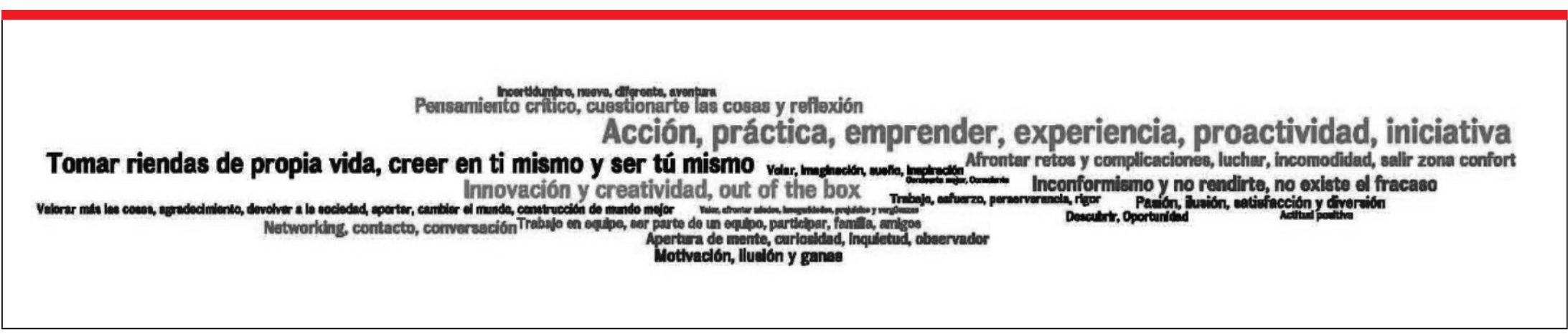

Figura 3. Nubes de tags de las ideas recogidas en las entrevistas a iNNoVaNDeRs. Fuente: Elaboración propia

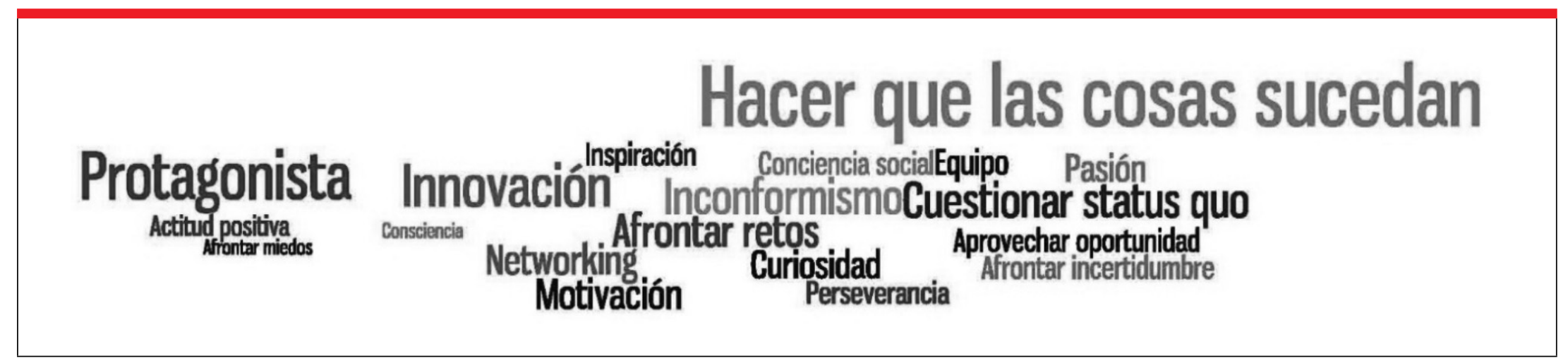

Figura 4. Nubes de tags de las palabras clave en las que se han resumido las ideas clave recogidas en las entrevistas a iNNoVaNDeRs. Fuente: Elaboración propia 
De entre las competencias que se trabajan en iNNoVaNDiS, las y los iNNoVaNDeRs destacan sobre todo la capacidad de tomar la iniciativa y pasar a la acción $(n=42)$. Sin duda alguna, la orientación hacia la práctica que subyace al programa, y la capacidad de trabajar en proyectos y retos reales de organizaciones con las que pueden tener un contacto directo durante su etapa formativa es uno de los activos más destacados y apreciados al llegar al mundo laboral. El objetivo de que iNNoVaNDiS se convierta pues en un programa de entrenamiento en el que trabajar y fracasar en el desarrollo de competencias orientadas a la carrera profesional tiene por tanto una racionalidad que conlleva una aportación de valor real $(n=31)$. Esta capacidad de pasar a la acción está a su vez muy vinculada con la competencia de pensamiento crítico, por la cual el programa busca que los participantes en él sean capaces de formularse las preguntas adecuadas, y de pensar y reflexionar con rigor sobre las posibles respuestas $(\mathrm{n}=21)$.

Otro de los activos fundamentales que constituyen la propuesta de valor del programa radica en la diversidad del entorno social que forma parte del mismo, a saber, las personas que participan de manera directa y activa en el programa, así como la amplia de red de agentes del ecosistema de innovación que colaboran con el mismo $(n=20)$. A su vez, según las personas consultadas, el programa les permite desarrollar una amplia gama de amistades, y conocer una cantidad heterogénea de proyectos y experiencias $(n=38)$ que les permite ampliar la visión que los alumnos tienen de la vida $(n=16)$ y del mundo $(n=12)$. Esta amplia red de contactos que desarrollan durante su participación en el programa, trasciende la temporalidad del mismo, ya que una vez de haber llegado al mundo laboral, los iNNoVaNDeRs sienten que pueden volver a contactar e incluso llegar a poder trabajar de manera conjunta con dichos contactos, dados los diferentes perfiles profesionales adquiridos por los antiguos compañeros, senseis y pequeños saltamontes.

La atención que en el programa se le presta a la persona $(n=16)$, a sus actitudes personales $(n=16)$, a sus ilusiones $(n=13)$ así como a la necesidad de superar sus miedos $(n=5)$ son también valorados por los alumnos una vez de haber terminado sus estudios de iNNoVaNDiS. Las personas entrevistadas también destacan la inquietud que el programa les transmite, tanto en lo referente a la capacidad de buscar oportunidades, como a encontrar soluciones que puedan dar respuesta a las mismas $(n=28)$. Esta proactividad a la hora de tomar la iniciativa para emprender e innovar, aportando valor y generando riqueza en el entorno local de manera sostenible en el tiempo, de manera que éste pueda cambiar y adaptarse a las nuevas demandas globales ( $n=30)$, es algo que los iNNoVaNDeRS llevan más allá de las aulas. iNNoVaNDiS es pues considerado por las personas consultadas como un programa diferente, que ayuda a desarrollarse personal y profesionalmente, ayudando a las personas que lo cursan a buscar su identidad y su razón de ser, y a intentar cambiar los entornos y situaciones personales y profesionales en los que se encuentran. Un programa necesario, riguroso, divertido, con un objetivo claro, con un sentido $\mathrm{y}$ una racionalidad que son agradecidas en y por el mundo profesional. 
Tras estos análisis se quiso afinar un poco más y analizar las 222 declaraciones de las 48 personas entrevistadas con relación a las características del perfil emprendedor, las emociones, los valores, las actitudes y las competencias que se trabajan en el programa iNNoVaNDiS. Para ello, se identificó cada idea clave con una característica del perfil emprendedor, una emoción, un valor, una actitud y una competencia, y se contabilizó cuántas declaraciones recogían cada una de estas variables. En el anexo1 se recopilan todas las tablas con sus correspondientes frecuencias.

A modo de resumen podemos resaltar que la característica del perfil emprendedor que trabaja el programa iNNoVaNDiS que ha sido más veces citada es la que dice que "debe ser una persona innovadora y con visión de futuro, orientación al mercado y al crecimiento para poder identificar oportunidades" (27\% de las declaraciones). Por otra parte, la emoción que trabaja el programa iNNoVaNDiS que ha sido más veces citada es la diversión (14\% de las declaraciones). Si hablamos de valores, el valor que trabaja el programa iNNoVaNDis que ha sido más veces citada es el autoconocimiento y superación personal (55\% de las declaraciones) y, dentro de este, sobre todo el sentido de la iniciativa (11\%). Y, en cuanto a las actitudes, la actitud que trabaja el programa iNNoVaNDis que ha sido más veces citada es la motivación de logro (31\% de las declaraciones).

La competencia genérica que trabaja el programa iNNoVaNDiS que ha sido más veces citada es la "automotivación: afrontar las propias capacidades y limitaciones, empeñándose en desarrollarlas y superarlas para ocuparse con interés y cuidado en las tareas por realizar" (17\% de las declaraciones). Y, por último, la macro competencia específica que trabaja el programa iNNoVaNDiS que ha sido más veces citada es la "capacidad de reflexión en acción, desarrollando su comportamiento creativo, capacidad de prospectiva" (49\% de las declaraciones).

\section{DISCUSIÓN}

Los resultados descritos en esta última sección del artículo demuestran cómo el impacto de iNNoVaNDiS va mucho más allá de las aulas y cómo efectivamente éste logra tener un impacto sobre los valores, las actitudes, las competencias, y la forma en la que se gestionan las emociones en entornos profesionales.

iNNoVaNDiS se centra en la persona emprendedora como alguien que es capaz de identificar oportunidades, hacer frente a la incertidumbre y la ambigüedad, es capaz de generar un orden a partir del caos, inicia, desarrolla, logra y se anticipa (incluso promueve) al cambio. Son varios los retos a los que iNNoVaNDiS se enfrenta en estos momentos de cambios legislativos en las universidades, dominadas por las acreditaciones oficiales y la evaluación que éstas realizan de los resultados a corto plazo. Confiamos que de la misma manera que el programa supo innovar en la educación emprendedora desde su creación en 2005, dicha capacidad de anticipación y cambio se siga manteniendo en el futuro. 


\section{REFERENCIAS}

Alcaraz, R. (2011). Perfil del Emprendedor, un Estudio Comparativo entre Universitarios de Países de Iberoamérica (Tesis doctoral). Universidad de Deusto, San Sebastián.

Alda, R. F. (2010). Perfil Emprendedor de los estudiantes de la Facultad de Economía y Administración de la Universidad Católica del Norte (Antofagasta, Chile) (Tesis doctoral). Universidad de Deusto, San Sebastián.

Ajzen, I. (1985). From intentions to actions: A theory of planned behavior. In J. Kuhl \& J. Beckmann (Eds.), Action-control: From cognition to behavior (pp. 1 1-39). Heidelberg: Springer.

Ajzen, I. (1991). The theory of planned behavior. Organizational Behavior and Human Decision Processes, 50(2), $179-211$. doi: https://doi.org/10.1016/0749-5978(91)90020-T

Baum, J. R., \& Locke E. A. (2004). The relationship of entrepreneurial traits, skills and motivation to subsequent venture growth. Journal of Applied Pshycology, 89(4), 587-598. doi: https://doi.org/10.1037/0021-9010.89.4.587

Bolton, B. \& Thompson, J. L. (2004). Entrepreneurs: Talent, Temperament, Technique. Oxford: Elsevier.

Breckler, S. J. (1984). Empirical validation of affect, behaviour, and cognition as distinct components of attitude. Journal of Personality and Social Psychology, 47(6), 1191-1205. doi: http://dx.doi.org/10.1037/0022-3514.47.6.1191

Brown, B. L. (1999). Entrepreneurship success stories: implications for teaching and learning. (Practice Application Brief No.3). Columbus, OH: ERIC Clearing on Adult, Career and Vocational Education.

Cardon, M.S., Wincent, J., Singh, J., \& Drnovsek, M. (2005). Entrepreneurial passion: the nature of emotions in entrepreneurship. Academy of Management Proceedings, 1, G1-G6.

Collins, L. A., Smith, A.J. \& Hannon, P.D. (2006). Applying a Synergistic Learning Approach in Entrepreneurship Education. Management Learning, 37(3), 335-354. doi: http://dx.doi.org/10.1177/1350507606067171

Comisión Europea (2008). Entrepreneurship in Europe, Green Paper (Brussels: Commission of the European Communities) Recuperado de https://goo.gl/GFzV8t

Cubeiro, J. C. (2008). Clase Creativa. Barcelona: Editorial Planeta.

Crant, M. (2000). Proactive behavior in organizations. Journal of Management, 26(3), 435-462. doi: http://dx.doi. org/10.1177/014920630002600304

Damasio, A. (2005). En busca de Spinoza. Neurobiología de la emoción y los sentimientos. Barcelona: Crítica.

Delors, J. (1996.). “Los cuatro pilares de la educación” en La educación encierra un tesoro. Informe a la UNESCO de la Comisión internacional sobre la educación para el siglo XXI. Madrid, España: Santillana/Unesco.

Eisenhardt, K.M. (1989). Making fast strategic decisions in high velocity environments. Academy of Management Journal, 32(3), 543-576. doi: http://dx.doi.org/10.2307/256434

Elexpuru, I. \& Yaniz, C. (2001). Valores y Organizaciones. Papeles de Ética, Economía y Dirección, 6, 79-93

Fishbein, M., \& Ajzen, I. (1975). Belief, attitude, intention, and behavior: An introduction to theory and research. Reading, MA: Addison-Wesley.

Florin, K., Karri, R., \& Rossite, N. (2007). Fostering entrepreneurial drive in business education: an attitudinal approach. Journal of Management Education, 31, 17-42. doi: http://dx.doi.org/10.1177/1052562905282023

Frank, A.I. (2007). Entrepreneurship and enterprise skills: a missing element of planning education? Planning, Practice \& Research, 22(4), 635-648. doi: http://dx.doi.org/10.1080/02697450701770142

Freire, A. (2004). Pasión por emprender. De la idea a la cruda realidad. Barcelona: Granica.

Garand, D. J. (2009). From intent to entrepreneurial action among multidisciplinary undergraduates students: the need to spread outside the business schools. Frontiers of Entrepreneurship Research, 29(6), Article 8. Recuperado de https://goo.gl/XYPi8P

Getley, R. (1979). Entrepreneurial drive. Industrial and Commercial Training, 11(1), 19-23. doi: http://dx.doi.org/10.1108/ eb003711 
Gibb, A. (2002). In pursuit of a new enterprise and entrepreneurship paradigm for learning: creative destruction, new values, new ways of doing things and new combinations of knowledge. International Journal of Management Review, 4(3), 233-269. doi: https://doi.org/10.1111/1468-2370.00086

Gibb, A., Haskins, G. \& Robertson, I. (2009). Leading the Entrepreneurial University. Meeting the entrepreneurial development needs of higher education institutions. Recuperado de http://www.ncge.com/publication/ leading_the_entrepreneurial_university.pdf

Goleman, D., Boyatzis, R., \& McKee, A. (2002). Primal leadership: Realizing the power of emotional intelligence. Boston: Harvard Business School

Gómez-Uranga, M., Zabala-Iturriagagoitia, J.M. \& Barrutia, J. (2016). Dynamics of Big Internet Industry Groups and Future Trends: A View from Epigenetic Economics. Heidelberg: Springer.

Goss, D. (2008). Enterprise ritual: A theory of entrepreneurial emotion and exchange. British Journal of Management, 19(2), 120-137. doi: https://doi.org/10.1111/j.1467-8551.2006.00518.x

Hall, B.P. (1995). Values shift: understanding personal and organizational transformation. Rockport: MA: Twin Lights Publication.

Heinonen, J. \& Hytti, U (2008). Enterprising individuals from an entrepreneurial university: entrepreneurship programmes in non-business and business schools. The Finnish Journal of Business Economics, 3, 325-340.

Hornaday, J.A. \& Aboud, J. (1971). Characteristics of successful entrepreneurs. Personnel Psychology, 24, 141-153. doi: https://doi.org/10.1111/j.1744-6570.1971.tb02469.x

Ibáñez, A. (2002). Actitudes emprendedoras de los estudiantes universitarios: medición y propuestas de actuación. Bilbao: Ediciones Mensajero.

Ibáñez, A., Fernández, I., Iglesias, A., Marigil, O. \& San Sebastián, P. (2014). La emoción de emprender desdela universidad: la universidad como vivero de personas emprendedoras. Recuperado de https://goo.gl/78TVu8

Ibáñez-Romero, A. \& Zabala-Iturriagagoitia, J.M. (2016). iNNoVaNDiS: A 10-Year Experience in Entrepreneurship and Innovation Education. En P. M. Papadopoulus, R. Burger \& A. Faria, (Eds.), Advances in Digital Education \& Lifelong Learning (Volume 2): Innovation and Entrepreneurship in Education (pp.195-224). Bingley (UK): Emerald Books.

Kawasaki, G. (2004). The art of the start: the time-tested, battle-handled guide for anyone starting anything. New York: Portfolio.

Kirby, D. A. (2007). Changing the entrepreneurship education paradigm. En A. Fayolle (Ed.), Handbook of Research in Entrepreneurship Education. (pp.21-33). Cheltenham: Edward Elgar.

Krauss, C. (2008). Las actitudes emprendedoras de los estudiantes de la Universidad Católica del Uruguay (Tesis doctoral). Universidad de Deusto, San Sebastian.

Krueger, N. F. \& Brazeal, D. V. (1994). Entrepreneurial potential and potential entrepreneurs. Entrepreneurship Theory and Practice, 18, 91-105. doi: http://dx.doi.org/10.1177/104225879401800307

Kwiatkowki, S. (2004). Social and Intellectual Dimensions of Entrepreneurship. Higher Education in Europe, 29(2), 205 220. doi: http://dx.doi.org/10.1080/0379772042000234848

Lankard, B.A. (1995). Career development in generation X. Myths and realities. Columbus, OH: ERIC Clearing on Adult, Career and Vocational Education.

Lebret, H. (2007). Start-up, what we may still learn from silicon valley. Scotts Valley, CA: CreateSpace.

Lloyd-reason, L., Sear, L., \& Mumby-Croft, R. (febrero 2009). How to link entrepreneurship education with the practical world of the entrepreneurs. Ponencia presentada en el EFMD Entrepreneurship Conference: The Role of Entrepreneurship Training in Tomorrow's Society. Barcelona, España.

McCelland, D.C. (1965). N achievement and entrepreneurship: a longitudinal study. Journal of Personality and Social Psychology, 1(4), 389-392. doi: http://dx.doi.org/10.1037/h0021956Morales, P. (2000). Medición de Actitudes en Psicología y Educación. Construcción de Escalas y Problemas Metodológicos. Madrid: Universidad Pontificia Comillas, ICAI-ICADE. 
Morris, M., \& Schindehutte, M. (2005). Entrepreneurial values and the ethic enterprise: an examination of six subcultures. Journal of Small Business Management, 43(4), 453-479. doi: https://doi.org/10.1111/j.1540-627X.2005.00147.x

Nunnaly, J. C. (1978). Psychometric Theory (2a ed.). New York: McGraw-Hill.

Obermair, D. (2008). Más pasión y sueños, menos infraestructura y experiencia. Infonomia Revista, 62, 35-62.

Quintero, C. (2007). Generación de competencias en jóvenes emprendedores. Recuperado de https://goo.gl/HYmWGU Retegui, J. (2001). La educación en el nuevo milenio- Gipuzkoa 2020. Mondragón, documento no publicado.

Robinson, P. (1987). Prediction of Entrepreneurship Based on Attitude Consistency Model (Tesis doctoral). Universidad de Brigham Young. Provo, Utah.

Robinson,P.B., Stimpson, D. V., Huefner, J.C.\&Hunt,H.K.(1991). Anattitudeapproach to theprediction of entrepreneurship. Entrepreneurship Theory and Practice, 15(4), 13-31. doi: https://doi.org/10.1177/104225879101500405

Römer-Paakkanen, T. \& Pekkala, A. (2008). Generating entrepreneurship and new learning environments from students' free time activities and hobbies. Liiketaloudellinen Aikakauskirja, 57(3), 341-361.

Saboia, F. \& Martín, N. (2006). Los rasgos psicológicos del emprendedor y la continuidad del proyecto empresarial: un estudio empírico de emprendedores brasileños. Recuperado de https://goo.gl/bUhgTd

Schumpeter, J. (1942). Capitalism, Socialism, and Democracy. New York: Harper \& Row.

Seligman, M. E. P. (2002). La Auténtica Felicidad. Barcelona: Ediciones Biblos.

Shapero, A. \& Sokol, L. (1982). The social dimensions of entrepreneurship. In Kent, C.A., Sexton, D.L., Vesper, K.H. (Eds.), Encyclopedia of Entrepreneurship. (pp.72-89) Prentice-Hall, Englewood Cliffs, N.J.

Siemon, C. \& Otter, N. (2007). Coaching academic entrepreneurship: how to overcome the knowing-doing-gap. Proceedings of the $2^{\text {nd }}$ European Conference on Entrepreneurship and Innovation, Utrecht University, Utrecht (The Netherlands), 08-09 November, pp 167-175.

Southon, M. \& West, C. (2005). The boardroom entrepreneur. London: Random House.

Timmons, J. A. (2000). New venture creation: Entrepreneurship for the 21st Century. Boston: Irwin-McGraw-Hill

Tracey, P. \& Phillips, N. (2007). The distinctive challenge of educating social entrepreneurs: a postscript and rejoinder to the special issue on entrepreneurship education. Academy of Management Learning and Education, 6(2), 264-271.

Trías de Bes, F. (2007). El Libro Negro del Emprendedor: No Digas que Nunca te lo Advirtieron. Barcelona: Editorial Urano. Unesco (1998). La Educación Superior en el Siglo XXI. Visión y Acción. Conferencia Mundial sobre la Educación Superior. París, 5-9 Octubre 1998. Recuperado http://unesdoc.unesco.org/images/0011/001136/113602So.pdf

Unión Europea (2006). Recomendación del Parlamento Europeo y del Consejo de 18 de diciembre de 2006 sobre las competencias clave para el emprendimiento permanente. Diario Oficial de la Unión Europea (2006/962/CE).

Urban, B. (2006). Entrepreneurship in the rainbow nation: effect of cultural values and ESE of intentions. Journal of Developmental Entrepreneurship, 11(3), 171-186. doi: https://doi.org/10.1142/S1084946706000386

Van Burg, E, Romme, A.G.L., Gilsing, V.A. \& Reymen, I.M.M.J. (2008). Creating university spin-offs: a science-based design perspective. Journal of Product Innovation Management, 25(2), 114-128. doi: https://doi.org/10.1111/ j.1540-5885.2008.00291.x

Villa, A. \& Poblete, M. (2007). Aprendizajebasadoen competencias. Una propuesta para la evaluación delas competencias genéricas. Bilbao: Mensajero.

Yaniz, C. \& Villardon, L. (2006). Cuadernos Monográficos de ICE; Planificar desde competencias para promover el emprendizaje: el reto de la sociedad del conocimiento para el profesorado universitario (vol. 12). Bilbao: Publicaciones de la Universidad de Deusto.

Yunus, M. (2006). Discurso de recogida del premio Nobel. Recuperado https://goo.gl/fTSWdq 


\section{APÉNDICE A}

Frecuencia con la que las personas entrevistadas hacen referencia a cada característica del perfil emprendedor que trabaja el programa iNNoVaNDis

\begin{tabular}{|c|c|c|}
\hline Características del perfil emprendedor & $\#$ & $\%$ \\
\hline $\begin{array}{l}\text { 1. Debe ser perseverante, comprometida, con determinación y energía, para poder } \\
\text { trabajar duro y afrontar los muchos sacrificios a los que se enfrentará. }\end{array}$ & 22 & $10 \%$ \\
\hline $\begin{array}{l}\text { 2. Debe tener iniciativa, flexibilidad, tolerancia al cambio, asunción de riesgos } \\
\text { moderados y no temer al fracaso, para poder afrontar situaciones de incertidumbre, } \\
\text { crecientes en entornos de alta velocidad como los actuales (Eisenhardt, 1989). }\end{array}$ & 29 & $13 \%$ \\
\hline $\begin{array}{l}\text { 3. Debe ser una persona innovadora y con visión de futuro, orientación al mercado y al } \\
\text { crecimiento para poder identificar oportunidades. }\end{array}$ & 60 & $27 \%$ \\
\hline $\begin{array}{l}\text { 4. Debe tener una elevada motivación de logro y optimismo que le empujen y le ayuden } \\
\text { a forjar el deseo de ser emprendedor. }\end{array}$ & 31 & $14 \%$ \\
\hline $\begin{array}{l}\text { 5. Debe tener altos niveles de autoestima y un control percibido interno que le permitan } \\
\text { afrontar los posibles fracasos y lanzarse a nuevos retos. }\end{array}$ & 25 & $11 \%$ \\
\hline $\begin{array}{l}\text { 6. Debe tener una disposición proactiva, iniciativa y una gran dosis de compromiso, } \\
\text { perseverancia y voluntad por lanzar su proyecto (Baum y Locke, 2004). }\end{array}$ & 24 & $11 \%$ \\
\hline $\begin{array}{l}\text { 7. También deben considerarse los valores personales del individuo comola honestidad, } \\
\text { la sensación de deber, la responsabilidad y el comportamiento ético (Saboia y Martin, } \\
\text { 2006; Quintero, 2007). }\end{array}$ & 9 & $4 \%$ \\
\hline $\begin{array}{l}\text { 8. Otros: networking, contactos, conversación, trabajo equipo, familia, amigos, } \\
\text { participar, ser parte }\end{array}$ & 22 & $10 \%$ \\
\hline TOTAL & 222 & $100 \%$ \\
\hline
\end{tabular}

Fuente: Elaboración propia. 
Frecuencia con la que las personas entrevistadas hacen referencia a las emociones estimuladas en el Programa iNNoVaNDiS

\begin{tabular}{|c|l|c|c|}
\hline \multirow{2}{*}{ Emociones } & & $\#$ & $\%$ \\
\hline \multirow{2}{*}{ Miedo } & $\begin{array}{l}\text { 1. Situaciones o sobre qué elementos está orientada la emoción: } \\
\text { fracaso, riesgo, futuro, al qué dirán, a hacer el ridículo }\end{array}$ & 20 & $9 \%$ \\
\cline { 2 - 4 } & 2. Frustración & 13 & $6 \%$ \\
\hline \multirow{2}{*}{ Disfrute } & 3. Diversión 3 & 1 & $14 \%$ \\
\cline { 2 - 4 } & $\begin{array}{l}\text { 4. Situaciones o sobre qué elementos está orientadala emoción: } \\
\text { incertidumbre }\end{array}$ & 9 & $4 \%$ \\
\cline { 2 - 4 } & 5. Sorpresa & 29 & $13 \%$ \\
\hline Vergüenza & 6. Controlar la vergüenza & 19 & $9 \%$ \\
\hline Otras & 7. No se hace referencia a ninguna emoción & 101 & $45 \%$ \\
\hline & & $\mathbf{2 2 2}$ & $\mathbf{1 0 0 \%}$ \\
\hline
\end{tabular}

Fuente: Elaboración propia.

Frecuencia con la que las personas entrevistadas hacen referencia a los valores incluidos en las categorías que se trabaja en el programa de entrenamiento iNNoVaNDiS

\begin{tabular}{|c|c|c|c|c|}
\hline Valores & & $\#$ & \multirow{2}{*}{\multicolumn{2}{|c|}{$\%$}} \\
\hline \multirow{9}{*}{$\begin{array}{l}\text { Autoconocimiento y } \\
\text { superación personal }\end{array}$} & 1. Humildad* & 6 & & \\
\hline & 2. Inconformismo $*$ & 14 & $6 \%$ & \\
\hline & 3. Sentido de la iniciativa* & 24 & $11 \%$ & \\
\hline & 4. Ser uno mismo & 6 & $3 \%$ & \\
\hline & 5. Responsabilidad & 9 & $4 \%$ & \\
\hline & 6. Crecimiento/ expansión & 22 & $10 \%$ & \\
\hline & 7. Logro / éxito & 9 & $4 \%$ & \\
\hline & 8. Autocompetencia / confianza & 19 & $9 \%$ & \\
\hline & 9. Paciencia/resistencia & 14 & $6 \%$ & \\
\hline \multirow{6}{*}{$\begin{array}{l}\text { Pertenencia a } \\
\text { la comunidad }\end{array}$} & 10. Empatía* & & $0 \%$ & \multirow[t]{6}{*}{$15 \%$} \\
\hline & 11. Colaboración desinteresada * & & $0 \%$ & \\
\hline & 12. Compromiso* & & $0 \%$ & \\
\hline & 13. Apertura* & 11 & $5 \%$ & \\
\hline & 14. Cooperación & 10 & $5 \%$ & \\
\hline & 15. Unidad / diversidad & 12 & $5 \%$ & \\
\hline \multirow{3}{*}{$\begin{array}{l}\text { Sentimiento de } \\
\text { justicia social }\end{array}$} & 16. Dar sentido a lo que hago* & 23 & $10 \%$ & \multirow[t]{4}{*}{$30 \%$} \\
\hline & 17. Progreso/innovación & 17 & $8 \%$ & \\
\hline & 18. Ética / responsabilidad & 9 & $4 \%$ & \\
\hline Otros & $\begin{array}{l}\text { 19. Actitud positiva, volar, imaginación,sueño, } \\
\text { inspiración }\end{array}$ & 17 & $8 \%$ & \\
\hline & TOTAL & 222 & $100 \%$ & $100 \%$ \\
\hline
\end{tabular}

Fuente: Elaboración propia. 
Frecuencia en la que las personas entrevistadas hacen referencia a las actitudes trabajadas en el programa iNNoVaNDis

\begin{tabular}{|c|c|c|c|c|}
\hline Actitudes & & $\#$ & \multicolumn{2}{|c|}{$\%$} \\
\hline \multirow{4}{*}{ Disposición proactiva } & 1. Proactividad & \multirow{2}{*}{24} & \multirow{2}{*}{$11 \%$} & \multirow{4}{*}{$26 \%$} \\
\hline & 2. Sentido de la iniciativa & & & \\
\hline & 3. Apertura de mente & 26 & $12 \%$ & \\
\hline & 4. Ser energético & 8 & $4 \%$ & \\
\hline \multirow{3}{*}{ Disconformidad } & 5. Creatividad & & & \multirow{3}{*}{$22 \%$} \\
\hline & 6. Innovación & T7 & $8 \%$ & \\
\hline & 7. Curiosidad & 32 & $14 \%$ & \\
\hline Control percibido interno & 8. Autoconfianza & 19 & $9 \%$ & $9 \%$ \\
\hline \multirow{5}{*}{ Motivación de logro } & 9. Rigor & 22 & $10 \%$ & \multirow{5}{*}{$31 \%$} \\
\hline & 10. Perseverancia & & & \\
\hline & 11. Compromiso & 9 & $4 \%$ & \\
\hline & 12. Autoeficacia & 14 & $6 \%$ & \\
\hline & 13. Pasión & 23 & $10 \%$ & \\
\hline \multirow[t]{2}{*}{ Otros } & $\begin{array}{l}\text { 14. Conocerte mejor, consciente, networkin, contacto, } \\
\text { conversación, trabajo equipo, ser parte, participar, } \\
\text { familia, amigos }\end{array}$ & 28 & $13 \%$ & $13 \%$ \\
\hline & TOTAL & 222 & $100 \%$ & $100 \%$ \\
\hline
\end{tabular}

Fuente: Elaboración propia. 
Frecuencia con la que las personas entrevistadas hacen referencia a las competencias genéricas aplicables a una persona emprendedora de entre las que propone el MDF

\begin{tabular}{|c|c|c|}
\hline Competencias Genéricas & $\#$ & $\%$ \\
\hline $\begin{array}{l}\text { 1. Tratamiento de conflictos y negociación: tratar y resolver las diferencias que surgen } \\
\text { entre personas y/o grupos en cualquier tipo de organización. }\end{array}$ & & $0 \%$ \\
\hline $\begin{array}{l}\text { 2. Pensamiento reflexivo: comportamiento mental que facilita el reconocimiento y el } \\
\text { crecimiento de los modos de pensar que utilizamos en la resolución de algún problema } \\
\text { o en la realización de alguna tarea. }\end{array}$ & 14 & $6 \%$ \\
\hline $\begin{array}{l}\text { 3. Uso de las TIC: utilizar las TIC como una herramienta para la expresión y la } \\
\text { comunicación, para el acceso a fuentes de información, como medio de archivo de } \\
\text { datos y documentos, para tareas de presentación, para el aprendizaje, la investigación } \\
\text { y el trabajo cooperativo. }\end{array}$ & & $0 \%$ \\
\hline $\begin{array}{l}\text { 4. Toma de decisiones: elegir la mejor alternativa para actuar, siguiendo un proceso } \\
\text { sistemático y responsabilizándose del alcance y consecuencias de la opción tomada. }\end{array}$ & \multirow{2}{*}{36} & \multirow{2}{*}{$16 \%$} \\
\hline $\begin{array}{l}\text { 5. Orientación al logro: realizar actuaciones que lleven a conseguir nuevos resultados } \\
\text { con éxito. }\end{array}$ & & \\
\hline $\begin{array}{l}\text { 6. Automotivación: afrontar las propias capacidades y limitaciones, empeñándose en } \\
\text { desarrollarlas y superarlas para ocuparse con interés y cuidado en las tareas a realizar. }\end{array}$ & 37 & $17 \%$ \\
\hline $\begin{array}{l}\text { 7. Adaptación al entorno: Afrontar situaciones críticas del entorno psicosocial, } \\
\text { mantenimiento un estado de bienestar y equilibrio físico y mental que permite a la } \\
\text { persona seguir actuando con efectividad. }\end{array}$ & 26 & $12 \%$ \\
\hline $\begin{array}{l}\text { 8. Comunicación interpersonal: relacionarse positivamente con otras personas a } \\
\text { través de una escucha empática y a través de la expresión clara y asertiva de lo que se } \\
\text { piensa y/o siente, por los medios verbales y no-verbales. }\end{array}$ & 22 & $10 \%$ \\
\hline $\begin{array}{l}\text { 9. Pensamiento creativo: comportamiento mental que genera procesos de búsqueda } \\
\text { y descubrimiento de soluciones nuevas e inhabituales en los distintos ámbitos de la } \\
\text { vida. }\end{array}$ & \multirow{3}{*}{35} & \multirow{3}{*}{$16 \%$} \\
\hline $\begin{array}{l}\text { 10. Creatividad: abordar y responder satisfactoriamente a situaciones de forma nueva } \\
\text { y original en un contexto dado. }\end{array}$ & & \\
\hline $\begin{array}{l}\text { 11. Innovación: dar respuestas satisfactorias a las necesidades y demandas personales, } \\
\text { organizativas y sociales, modificando o introduciendo elementos nuevos en los } \\
\text { procesos y en los resultados. }\end{array}$ & & \\
\hline $\begin{array}{l}\text { 12. Espíritu emprendedor: realizar proyectos por iniciativa propia, comprometiendo } \\
\text { determinados recursos con el fin de explotar una oportunidad, y asumiendo el riesgo } \\
\text { que ello acarrea. }\end{array}$ & \multirow{3}{*}{24} & \multirow{3}{*}{$11 \%$} \\
\hline $\begin{array}{l}\text { 13. Gestión de proyectos: preparar, dirigir, evaluar y hacer seguimiento de un trabajo } \\
\text { complejo de manera eficaz desarrollando una idea hasta concretarla en servicio o } \\
\text { producto. }\end{array}$ & & \\
\hline $\begin{array}{l}\text { 14. Pensamiento práctico: comportamiento mental que facilita seleccionar el curso } \\
\text { de acción más apropiado, atendiendo a la información disponible y a establecer el } \\
\text { proceso a seguir para alcanzar los objetivos con eficacia y eficiencia. Es el modo de } \\
\text { pensar dirigido a la acción. }\end{array}$ & & \\
\hline $\begin{array}{l}\text { 15. Otros: actitud positiva, pasión, ilusión, satisfacción, diversión, valorar más las } \\
\text { cosas, agradecimiento, devolver a la sociedad, aportar, } 2813 \% \text { cambiar el mundo }\end{array}$ & 28 & $13 \%$ \\
\hline TOTAL & 222 & $100 \%$ \\
\hline
\end{tabular}

Fuente: Elaboración propia. 
Frecuencia con la que las personas entrevistadas hacen referencia

a las macro-competencias específicas del programa iNNoVaNDiS

\begin{tabular}{|c|c|c|}
\hline Macro Competencias específicas & $\#$ & $\%$ \\
\hline $\begin{array}{l}\text { Macro-competencia 1: capacidad de reflexión en acción, desarrollando su } \\
\text { comportamiento creativo, capacidad de prospectiva, identificación de oportunidades } \\
\text { e implantación de nuevos proyectos. }\end{array}$ & 109 & $49 \%$ \\
\hline $\begin{array}{l}\text { Macro-competencia 2: capacidad de relacionarse en entornos cambiantes, participar y } \\
\text { gestionar equipos multidisciplinares y estar dispuesto y comprometido con el diálogo } \\
\text { permanente. }\end{array}$ & 36 & $16 \%$ \\
\hline $\begin{array}{l}\text { Macro-competencia 3: tomar las riendas de su propio destino, ser el guionista y } \\
\text { director de su propia experiencia vital asumiendo la responsabilidad de la misma y } \\
\text { buscar al emprendedor que lleva dentro. }\end{array}$ & 77 & $35 \%$ \\
\hline $\begin{array}{l}\text { Macro-competencia 4: capacidad de aprovechar las TIC de forma estratégica durante } \\
\text { todo el proceso emprendedor actuando bajo un sentido de la 'Urbanidad' Digital. }\end{array}$ & & $0 \%$ \\
\hline TOTAL & 222 & $100 \%$ \\
\hline
\end{tabular}

Fuente: Elaboración propia.

RIDU / Revista Digital de Investigación en Docencia Universitaria / ISNN 2223-2516

(c) Los autores. Este artículo es publicado por la Revista Digital de Investigación en Docencia Universitaria del Área de Institutional Research and Effectiveness de la Dirección de Aseguramiento de la Calidad, Universidad Peruana de Ciencias Aplicadas. Este es un artículo de acceso abierto, distribuido bajo los términos de la LicenciaCreativeCommons Atribución-CompartirIgual 4.0 Internacional. ( http://creativecommons.org/licenses/by-sa/4.0/), que permite el uso no comercial, distribución y reproducción en cualquier medio, siempre que la obra original sea debidamente citada. 